\title{
EXPERIÉNCIA INTERNACIONAL: UMA BIBLIOTECARIA BRASILEIRA NA BIBLIOTECA DO CONGRESSO DOS ESTADOS UNIDOS
}

\section{Célia Maria Ribeiro}

RESUMO: Relato de um período de nove meses trabalhando na Divisão Hispânica da Biblioteca do Congresso dos Estados Unidos, com uma bolsa de estudos patrocinada pela Fundação Lampadia através de sua representante no Brasil, VITAE Apoio à Cultura, Educação e Promoção Social. Focaliza dados históricos, números do acervo, estrutura física e quadro de pessoal de uma das mais tradicionais instituições americanas, considerada a maior biblioteca do planeta. Dá a conhecer alguns tipos de projetos desenvolvidos enfatizando a importância da experiência anterior para o bom aproveitamento e crescimento profissional, possibilitando ainda o compartilhamento com os pares quando da volta ao país de origem.

PALAVRAS-CHAVE: Biblioteca do Congresso - EUA; Intercâmbio profissional; Programas de treinamento profissional.

ABSTRACT: Reports a nine months internship spent at the Hispanic Division of The Library of Congress of the United States of America, sponsored by Lampadia Foundation through its Brazilian branch VITAE. Focus on history, collections, buildings and staff of one of the most traditional American institutions, which is considered the biggest library of the world. Describes the experience and knowledge gained as a result of participation in various projects, pointing out the importance of previous library expertise in order to take advantage to improve professional development and afterwards share the results with peers in the home country.

KEY-WORDS: USA - Library of Congress; International exchanges; Field work; Work experience programmes, Internship. 
$\mathrm{O}$ investimento que algumas instituições fazem para apoiar projetos e programas especiais

nas áreas da cultura, educação e promoção social são essenciais para o desenvolvimento profissional de pessoas dos países em desenvolvimento. Muitas vezes tornam-se oportunidades únicas de conhecermos lugares considerados modelos dentro da nossa área de atuação. Assim uma "Bolsa de Estudos da Lampadia Foundation para Treinamento de Bibliotecário/Especialista da Informação na Divisão Hispânica da Biblioteca do Congresso dos Estados Unidos", patrocinada pela Fundação VITAE, deu-me a oportunidade de trabalhar por nove meses nos Estados Unidos participando de atividades variadas, muitas das quais familiares, porque as rotinas de uma biblioteca especialmente no que se refere ao atendimento de usuários é muito parecida. O diferencial é observado nos recursos disponíveis na biblioteca, na forma como é tratada a questão da valorização profissional e no nível de investimento que estas instituições empregam na especialização das pessoas envolvidas.

As instituições que recebem um profissional estrangeiro para treinamento em suas dependências costumam fazer um minucioso levantamento, considerando principalmente a experiência anterior do candidato a fim de estabelecer um programa que efetivamente vá ajudá-lo a desenvolver uma nova habilidade e ao mesmo tempo torná-lo um membro produtivo na equipe de trabalho. A perfeita integração do profissional nas escalas de serviços e horários estabelecidos é fundamental para que assuma responsabilidades de um funcionário regular e sinta-se ajustado às normas locais.
Experiências anteriores demonstram que deve-se destinar um bom espaço físico, um computador ligado à rede com e-mail disponível, acesso a uma máquina fotocopiadora e todo o material necessário para a execução das atividades. Alguns privilégios no uso da coleção da biblioteca também ajudam a tornar o ambiente de aprendizado positivo e acolhedor, o que faz a diferença para que um treinamento seja eficiente.

Ao partir para uma atividade deste porte, as expectativas são muito grandes $\mathrm{e}$ muitas vezes a normalidade de um ambiente de trabalho que nos é apresentada parece um pouco frustrante. Mas no meu caso, só o fato de adentrar as dependências daquela que é considerada pelo Bibliotecário do Congresso James Billington uma "imensa universidade eletrônica", já é uma grande recompensa.

A bolsa de estudos para a Divisão Hispânica no ano de 2000 oferecia um trabalho especificamente na área de Referência na Sala de Leitura juntamente com o staff, constituído de dois bibliotecários e cinco especialistas conhecidos como recommending officers, que são também responsáveis pela seleção de materiais para aquisição.

Tive oportunidade de participar de vários projetos, fazer visitas técnicas, assistir a seminários, conferências e workshops, que ajudaram na familiarização com as características específicas da Biblioteca do Congresso. As políticas de acesso público aos catálogos online, regulamentos, serviços de referência, desenvolvimento de coleções, catalogação, circulação, além de outras atividades inerentes ao seu papel de "Ministério da Educação", já que os Estados Unidos não possuem um órgão com esta função, foram assimiladas no dia a dia. 
Integrada à escala de serviços de atendimento e assistência ao público na Sala de Leitura quanto ao uso do Sistema Integrado de Bibliotecas (Voyager), para pesquisas no catálogo online da LC e outras bases de dados acessíveis na rede local (em dezembro/2000 cerca de 60 bases de dados comerciais estavam disponíveis e mais 20 em fase de teste), pude conhecer melhor o acêrvo, o sistema de classificação e a localização física dos materiais.

Diariamente chegam solicitações de pesquisa e de informações variadas, provindas tanto dos Estados Unidos como de outros países. $\mathrm{O}$ atendimento obedece a algumas normas, especialmente levando em consideração que a prioridade da Biblioteca do Congresso é atender senadores e deputados e outros membros do governo americano e depois à comunidade em geral.

Muitos setores da Biblioteca têm carência de pessoal com conhecimentos em certas línguas e culturas, este é o caso da língua portuguesa e do Brasil. Isto foi um ponto positivo durante minha estadia lá, embora deixando de praticar a língua local, pude ajudar muito nas traduções de alguns documentos para o português, colaborando na definição de têrmos regionais para complementar pesquisas ou trabalhos que estavam sendo desenvolvidos.

Dentre estes trabalhos estão: Revisão/tradução da página web do Handbook of Latin American Studies, que possibilitou a disponibilização online da sua versão em português <http://lcweb2.loc.gov/hlas/portugues>; tradução da Homepage MARC Code List for Organizations e What is a MARC Organization Code for? <http://lcweb.loc.gov/marc/organizations /form-por.html>, para o Network Development and MARC Standards Office, que tem ajudado muito as instituições brasileiras quando da solicitação do Código MARC que identifica as instituições participantes de redes de compartilhamento e cooperação usando o Formato MARC; versão para o português da página inicial do catálogo online The Library of Congress Online Catalog. Ainda envolvendo o aspecto tradução, foi solicitada pela Divisão de Música um estudo sobre uma música folclórica brasileira para apresentação em um evento; e a revisão do artigo "Brazilian Chapbooks: the original books online" para o American Folklife Center, para fins de publicação no Boletim local Folklife Center News.

Muitos eventos são organizados durante o ano todo e naqueles referentes ao Brasil ou Portugal, pude prestar assistência na montagem de exposições, na localização e escolha do material a ser exposto, na elaboração e/ou revisão das legendas e realizando levantamento bibliográfico temático.

Outros projetos:

- Organização cronológica de cartas, cartões, convites e telex (décadas de 30 a 90) de arquivo documental de Romy Medeiros, feminista brasileira cuja coleção foi adquirida pela Biblioteca do Congresso. Este material está em fase de processamento e tem sido feito com a colaboração de voluntários.

- Normalização de dados cadastrais e bibliográficos de uma coleção de Literatura de Cordel constituída de 180 publicações e 10 posters, doados pela Fundação Roberto Marinho através da embaixada brasileira nos Estados Unidos como parte do projeto "Gifts to the Nation" - a Biblioteca do Congresso abriga uma das maiores coleções de 
literatura de cordel conhecidas, conta com mais de 10.000 itens.

O trabalho começou com a conferência e correção de uma listagem do material existente e checagem dos dados com os originais. A digitação tinha sido feita por uma estagiária americana que não tinha a mínima noção do que significam palavras com cedilha e acentuação. Devido às características próprias deste tipo de publicação e às particularidades da língua portuguesa e à grande incidência de regionalismos esta etapa foi bastante trabalhosa. A transcrição de dados exige atenção, pois a grafia costuma apresentar erros que não devem ser corrigidos respeitando as normas de catalogação, não esquecendo de acrescentar as notas correspondentes nos campos específicos. Embora não exista a intenção de disponibilizar esta base de dados em Formato MARC, pensou-se que deveriam ser observadas pelo menos algumas regras a fim de normalizar as entradas de assuntos e autores. Foi feita também uma seleção por assuntos: crianças, política e história, religião, folclore, ecologia e os títulos e notas foram traduzidos para o inglês.

$\mathrm{O}$ fato de ter como coordenadora uma especialista luso-brasileira, Dra. Iêda Siqueira Wiarda, ajudou muito na interpretação desta coleção e além disto me ensinou muito da nossa história e cultura.

- Compilação de bibliografia sobre Macau e as influências portuguesas no Oriente, para complementar publicação dos trabalhos apresentados num Simpósio sobre Macau realizado na Biblioteca do Congresso em setembro de 1999.

- Preparo e padronização de lista bibliográfica de materiais recebidos da República Dominicana e Portugal para o projeto "Gifts to the Nation", segundo a norma A Manual of Style da University of Chicago Press.

Outras Instituições freqüentemente solicitam colaboração à Divisão Hispânica no que se refere à interpretação de documentos em língua portuguesa. Um destes trabalhos foi a revisão de nomes de autores brasileiros para o Projeto bilingüe Russo-Inglês "Meeting of Frontiers" de digitalização de textos.

Muitas consultas ao Brasil foram feitas a fim de obter informações variadas, desde dados pessoais ou institucionais relacionados com Afro-Brasileiros em Salvador/Bahia, até informações específicas de registros bibliográficos no Formato MARC utilizados pela UNICAMP, ou indicação de autoridades brasileiras em determinados assuntos para participar de eventos na Biblioteca do Congresso.

Em visita técnica a outros setores pude acompanhar as rotinas dos recommending officers no setor de Aquisição quanto a: indicação de compra de materiais relacionados em catálogos de editores; definição das prioridades de catalogação do material recebido (livros, revistas) referentes a Brasil e Portugal; seleção de material recebido por doação ou intercâmbio (descarte, devolução ou preparo técnico); projeto de Aquisição, Substituição e Recuperação de material extraviado; seleção/descarte de catálogos de exposições.

Na Divisão de Preservação e Conservação que é dividida em Book \& Paper Section, Preventive Conservation, Preservation Refformating Division e Binding \& Collection Care Division, foram apresentados todos os setores e demonstradas as técnicas utilizadas, tanto na preservação e conservação quanto em restauração. Na época da visita, a coleção 
de Thomas Jefferson que foi destaque nas comemorações do bicentenário da Biblioteca, era uma das prioridades.

Conhecer Prints \& Photographs Reading Room foi muito interessante, foi apresentada a organização das diversas coleções de fotografias e outros tipos de imagens. Explicou-se o porquê de algumas decisões na hora de definir como o acervo será distribuído, se por autores, coleções ou assuntos.

Outro local que guarda tesouros dentro da Biblioteca do Congresso é a Divisão Geography and Maps, existem exemplares únicos de mapas históricos e visitar esta coleção é uma verdadeira aula de história, geografia e de cultura geral.

Outras Atividades:

Visitas/tours: Main Reading Room, Preservation \& Conservation, Collection Management, Geography and Maps, Prints \& Photographs, Newspaper and Current Periodicals, Acquisitions, Cataloging, Rare Books \& Special Collections, American Folklife Center, Manuscripts, Network Development and MARC Standards Office, Business Reference Services.

Outras visitas: Biblioteca Pública de Washington, DC, NIH - National Institute of Health, MD.

A parte técnica foi reforçada com a participação em workshops e treinamentos que são oferecidos regularmente: MARC Validation, Creating Authorities, LC Printed Subject Headings, Assign of Subject Headings, LC Classification, OCLC Passport to Windows.

Enfim, toda a bagagem que trouxe da UNICAMP, a experiência prática (atendimento ao público, uso de recursos automatizados, comunicação eletrônica, utilitários (Windows, Netscape, etc.), formato MARC, resolução de problemas técnicos básicos, localização de materiais nas estantes, interpretação de termos relacionados aos sistemas de busca e tradução de manuais técnicos para o português, linguagem HTML, etc.), e a reciclagem constante, foi muito útil tanto no desempenho das atividades diárias, quanto na assimilação de novos conhecimentos quando da participação nos eventos e treinamentos.

\section{HISTÓRICO DA LIBRARY OF CONGRESS}

A Biblioteca do Congresso foi criada no ano de 1800 com uma coleção de 3.000 volumes destinados a servir de referência para os membros do Governo americano deputados e senadores. O acervo deveria conter os livros necessários para que fosse dada a conhecer a história americana e abrigasse as principais coleções universais do conhecimento. Além disto serviria de subsídio para a elaboração de leis e políticas de relações internacionais entre os Estados Unidos e $\mathrm{o}$ resto do mundo. A verba destinada à Biblioteca foi de $\$ 5.000$.

Em 1814 durante uma invasão de tropas inglesas ao Capitólio onde funcionava a Biblioteca, o acervo foi incendiado. Em 1815 o Congresso aprovou a compra da biblioteca pessoal do ex-presidente Thomas Jefferson (1801-1804 e 18051808), com 6.487 livros que se tornou o núcleo do que é hoje considerada a maior biblioteca do planeta. O valor aprovado para a compra do acervo foi de $\$ 23.950$, considerada uma boa quantia para a aquisição de livros, ferramenta essencial para a criação de uma democracia sadia. 
Thomas Jefferson tinha uma coleção eclética classificada por assuntos. Inspirado em Francis Bacon dividia o conhecimento em: Memory (História), Reason (Filosofia) e Imagination (Artes). Jefferson sempre dizia que "Não existe nenhum assunto que um membro do Congresso não tenha ocasião de pesquisar ou referir-se", sendo ele próprio um pesquisador incansável, contribuiu para o início de uma coleção que contempla todos os assuntos possíveis, além da diversidade dos materiais que estão armazenados na LC.

A história mostrou aos americanos que havia necessidade de conhecer melhor os outros países quando uma guerra entre Estados Unidos e México (1846-1848), fez com que fosse aprovada a compra de todas as constituições e leis mexicanas, além de um jornal publicado na cidade de Vera Cruz. E assim, abriu-se espaço para a entrada de outras obras provindas de outros países, escritas em línguas que até hoje muitos não conseguem ler e que passaram a ser incorporadas ao acervo democratizando o conhecimento $\mathrm{e}$ divulgando outras culturas.

No ano de 1851 outro incêndio destruiu parte da biblioteca e dois terços da coleção original. Por ocasião da Comemoração do Bicentenário da Biblioteca em 2000, foi feita uma tentativa de reconstrução da biblioteca de Thomas Jefferson, mas apesar de todos os esforços ainda faltam cerca de 900 itens para que seja possível ver reunidos novamente estes volumes históricos.

Hoje o acervo de 119 milhões de itens está armazenado em cerca de 530 milhas de estantes (mais ou menos $861 \mathrm{~km}$ ) e 22 salas de leitura $(1$ geral e 21 especializadas), sendo: 18 milhões de livros, 53 milhões de manuscritos, 12 milhões de fotografias, 4 milhões de mapas, 2 milhões de gravações, além de milhares de outros materiais em suportes variados: filmes, pinturas, arquivos digitais, panfletos, caricaturas, posters, instrumentos musicais, peças patenteadas, história em quadrinhos, etc.

A área física está distribuída em três prédios situados no centro de Washington, Distrito de Columbia: o Thomas Jefferson Building - inaugurado em 1897 e restaurado durante 10 anos tendo sido reinaugurado em 1997, John Adams Building entregue em 1930 e o James Madison Memorial Building de 1980. Está em fase final de construção um novo prédio em Fort Mead, Maryland, que foi projetado para a guarda de materiais que precisam de condições especiais de armazenamento como filmes de acetato, altamente inflamáveis.

O orçamento de \$ 547.2 milhões para 2001 prevê a cobertura de vários itens: salários, móveis, projetos especiais como digitalização, preservação, segurança, redes de computador, manutenção do Sistema Integrado de Bibliotecas (ILS/Voyager).

A Biblioteca do Congresso iniciou a alimentação do seu catálogo on-line em 1968 e existem hoje 27 milhões dados catalográficos na rede, sendo que 50.000 foram também transpostos em suporte eletrônico.

O Desenvolvimento de Coleções é coordenado pelos recommending officers que são pessoas especializadas em determinados assuntos ou regiões e que são preparadas para

decidir o quê será adquirido pela LC que recebe 22.000 itens diariamente. Cerca de 10.000 destes itens são incorporados ao acervo após passarem por todo o processamento e preparo técnico incluindo a encadernação, que chega a 
perfazer um valor de US\$ 100.00 a cada volume.

A maioria da coleção provém do Depósito Legal - a LC abriga o U.S. Copyright Office desde 1870, e guarda registros de propriedade intelectual de compositores, gravadores (gravuras), cartunistas, criadores de mapas, arranjadores musicais, fotógrafos, jornalistas, cineastas, criadores de posters, arquitetos, engenheiros, publicitários, web designers, autores de discursos, criadores de cartoons entre outros.

As doações atingem $75 \%$ das entradas, e o restante são adquiridos através de compras, publicações de agências governamentais, intercâmbio e Catalogação na Fonte.

Os itens não selecionados vão para outras agências governamentais, instituições educacionais, organizações sem fins lucrativos e isentas de taxas nos Estados Unidos ou para intercâmbio nacional e internacional.

Cerca de 460 línguas estão representadas na coleção e todos os assuntos possíveis, porém predominam: economia, política, história, cultura, estatísticas, religião, bibliografias, epidemiologia na América Latina. Não são selecionadas: obras didáticas, traduções, ficção, literatura infantil, medicina clínica, agricultura, salvo casos especiais de autores premiados ou outro fato histórico de interesse atual que sejam incluídos nas prioridades de assuntos a serem adquiridos. As obras de medicina e agricultura são encaminhadas às respectivas bibliotecas nacionais: National Library of Medicine a National Library of Agriculture.

O quadro de pessoal em 2000 contava com um total de 4.200 funcionários: bibliotecários, especialistas e pessoal de suporte, sendo que cerca de 400 deles são dedicados exclusivamente ao atendimento do Congresso e do governo americano em geral. A biblioteca de Direito (Law Library) que abriga todas as publicações da área e tem normas muito diferenciadas das outras salas de leitura, é a maior responsável pelo atendimento deste público.

\section{DIVISÃO HISPÂNICA}

A Divisão Hispânica conta com treze funcionários, cinco deles dedicados ao Handbook of Latin American Studies (HLAS), 4 bibliotecários e os demais são especialistas em países latino americanos, Brasil, Portugal e outros países de língua portuguesa. No verão e outono conta-se com Interns - estudantes de várias áreas que são selecionados para prestar serviços neste período. Existem também pessoas que prestam serviços voluntários e aqueles provindos de projetos especiais financiados por instituições internacionais como Lampadia (VITAE/Brasil, Antorchas/Argentina, Andes/Chile), que trabalham na Biblioteca do Congresso nos programas especiais oferecidos em períodos determinados, normalmente por um ano.

A missão principal da Divisão Hispânica é selecionar publicações da Espanha, Portugal, América Latina e Caribe, preparar publicação de guias, bibliografias e estudos específicos como o Handbook of Latin American Studies uma bibliografia anotada anual, ferramenta básica de referência e aquisição para todos os países da região.

Responsável também pela orientação de pesquisas envolvendo os países abrangidos pela coleção de referência constituída de 4.000 volumes na Sala de Leitura, sendo que a coleção geral possui 200.000 livros só sobre o Brasil. 
Os contatos com a Biblioteca do Congresso e as pesquisas continuam a acontecer, tanto para fornecer informações daqui, quanto para pedir sugestões e opiniões do lado de lá. É muito importante ter canais de comunicação de certa forma informais, porque na prática os acessos são um pouco restritos e a burocracia dificulta o desenvolvimento de atividades não planejadas com bastante antecedência.

A experiência relatada neste texto tem a finalidade de demonstrar que existem oportunidades de realizar aprimoramento profissional fora do Brasil. É preciso ter certa experiência e preparo, de forma que o perfil seja compatível com as exigências do programa.

Em síntese, considero que toda a experiência em qualquer área da biblioteca, a busca da reciclagem profissional constante e o domínio de outras línguas, abrem as portas, mesmo se não tivermos domínio de alguns assuntos muito específicos da área. Devemos levar em conta que em tempos de globalização, o que se busca é a criação de canais entre diferentes culturas, mesmo que algumas sejam mais evoluídas que as outras, sempre haverá algo a acrescentar.

\section{REFERÊNCIAS BIBLIOGRÁFICAS}

1. AMERICAN treasures of the Library of Congress, memory, reason, imagination. New York: Harry N. Abrams, 1997.

2. BIBLIOTECA de sonhos. Semana da Unicamp, Campinas, SP, ano 2, n. 83, p. 6, 21-27 fev. 2000.

3. COLE, John Y. Jefferson's legacy: a brief history of the Library of
Congress. Washington, DC: Library of Congress, 1993. 103 p.

4. COLE, John Y. The Thomas Jefferson Building: book palace of the American people. Lancaster, Steckel Printing, s.d. (folder).

5. ESTÁGIO no exterior: depoimento. Interface: Informativo do Sistema de Bibliotecas da UNICAMP, Campinas, SP, ano 2, n. 1, p. 8, dez. 2000.

6. FINEBERG, Gail. Congress Oks \$ 547.2 million budget for LC. The Gazzete, Washington, DC, v. 12, n. 1, p. 1, 12 jan. 2001.

7. GRAIEB, Carlos. O museu de tudo. Veja, São Paulo, SP, ed. 1590, n.12, p. 144-146, 24 mar. 1999.

8. LIBRARY OF CONGRESS (Estados Unidos). Library of Congress Hispanic and Portuguese collections: na illustrated guide. Washington, DC, 1996. $84 \mathrm{p}$.

9. SAAVEDRA, Claudia Cuevas. My 10 months as a Lampadia fellow at the Library of Congress, USA. SALALM Newsletter, Austin, TX, v. 28, n. 1, p. 7, aug. 2000.

10. SOUZA, Yvonne. The training of international librarians. College \& Research Libraries, Chicago, IL, v. 61, n. 2, p. 110-113, 120, feb. 2000.

11. THE HISPANIC Room in the Library of Congress. Washington, DC: Library of Congress, s.d. 16 p.

12. THE LIBRARY of Congress: 25 questions most frequently asked by visitors. Washington, DC, aug. 1999. (folder). 
Célia Maria Ribeiro

Universidade Estadual de Campinas

Especialista em Geração de Banco de Dados e

Acesso a Base de Dados - UFRJ

Bibliotecária de Sistemas Automatizados

UNICAMP - Biblioteca Central

C.P. 6136 Cidade Universitária

13081-970 Campinas - SP

celiam@obelix.unicamp.br 